\title{
Load Response Analysis of Asphalt Pavement
}

\author{
Xiao Zhijun ${ }^{1,2}$ and Luan Liqiang ${ }^{3,4}$ \\ ${ }^{1}$ Tongji University, China \\ ${ }^{2}$ Key Laboratory of Road and traffic Engineering of the Ministry of Education, Shanghai, China \\ ${ }^{3}$ Guangxi Key Laboratory of Geomechanics and Geotchniacal Engineering Guilin China; \\ ${ }^{4}$ Guilin University of Technology, Guilin, China
}

\begin{abstract}
Based on the filed data of Fuzhou test road, load response regulation of nonlinear pavement structure was analyzed in this paper; Mechanics software was adopted to analyze linear elastic and nonlinear of the pavement structure, analyzed results and road filed data were compared, and determine the correlation between them and the field data.
\end{abstract}

\section{Introduction}

In recently years, loading reaction on Asphalt pavement gradually become a new research direction, with the purpose of studying the behaviors reaction upon different conditions on asphalt pavement radically. However due to limited financial and technical means, current research is mainly conducted by the mechanical analysis and theoretical calculation, which was lack of support of field data, obtained very limited loading response data through Experimental road paving. This article relies on the field data inspected from Fuyang high speed test road, NO.2 test section, carrying the in-depth analysis of load response of asphalt pavement.

\section{Introduction of the test road}

The structural of the Fuzhou test road is a typical longlife pavement composition, as shown in Fig. 1, adopting SMA asphalt mixture as the surface layer, other asphalt layers are made of SBS modified asphalt mixture, using local limestone and basalt in Fuyang as aggregate.

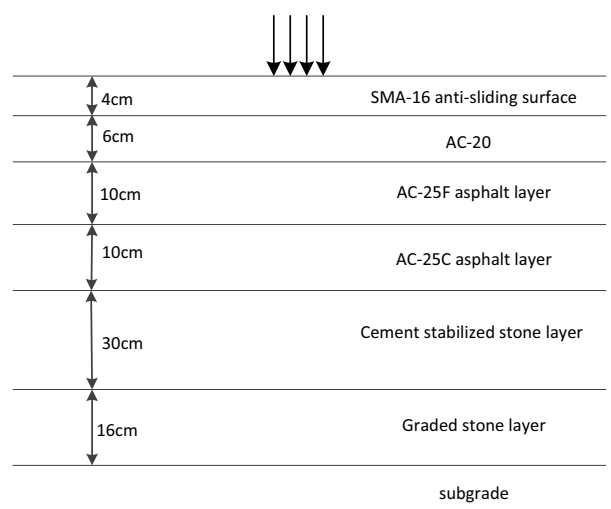

Figure 1. Test road structural form.
A lot of stress and strain sensors were laid under the test road, to measure the load response when vehicles pass by. Sensors buried in each structure layer of the wheel path and the apparatus are shown in Fig. 2 to Fig. 3.

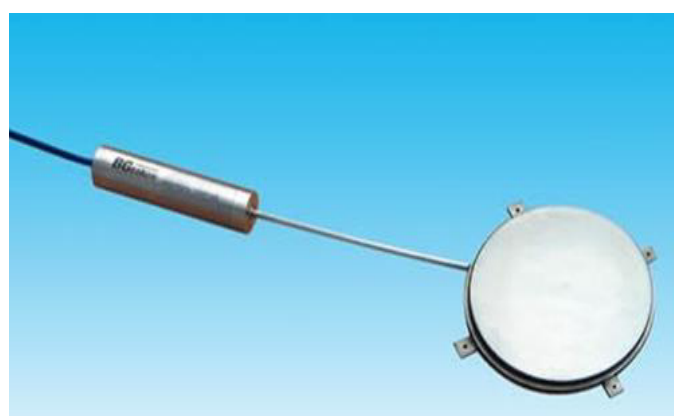

Figure 2. Earth pressure cell.

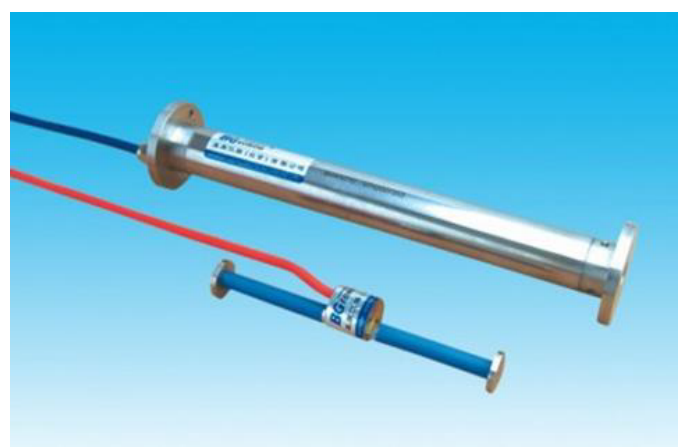

Figure 3. Embeded strain gage.

\section{Test data on experimental road}

Trucks with rear axle of $100 \mathrm{KN}$ were used as standard vehicle, from a distance of $20 \mathrm{~m}$ to the instrument Embedment position, marching forward at $10 \mathrm{~km} / \mathrm{h}$ and continuing the driving for another $20 \mathrm{~m}$ after reaching the embedment position. Data were recorded every $0.01 \mathrm{~m}$, 
after wavelength and temperature correction treatment, the result are shown as Fig. 4 Fig. 9.

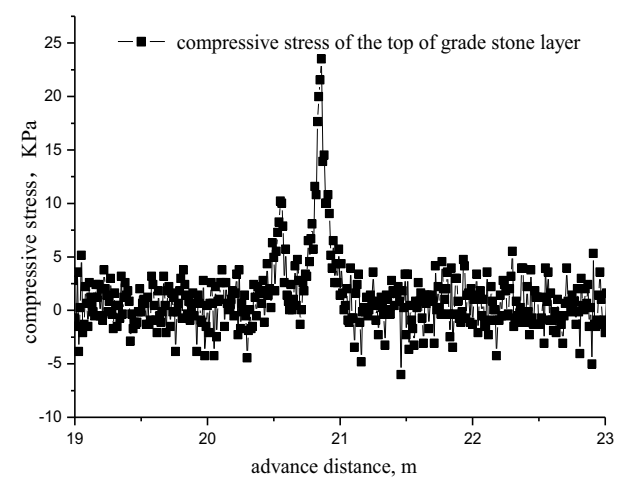

Figure 4. Compressive stress of the top of graded stone.

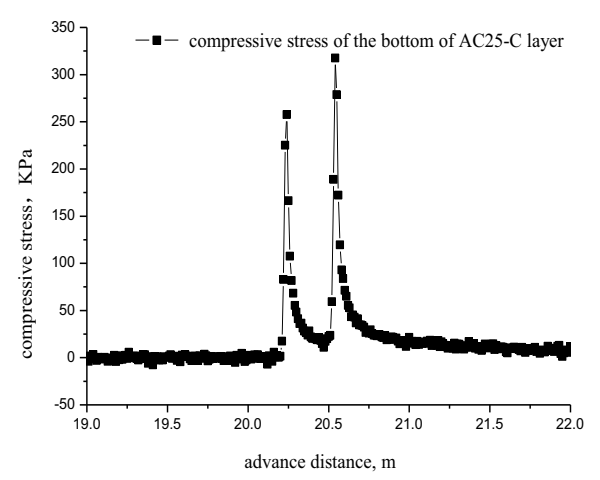

Figure 5. Compressive stress of the bottom of AC25-C.

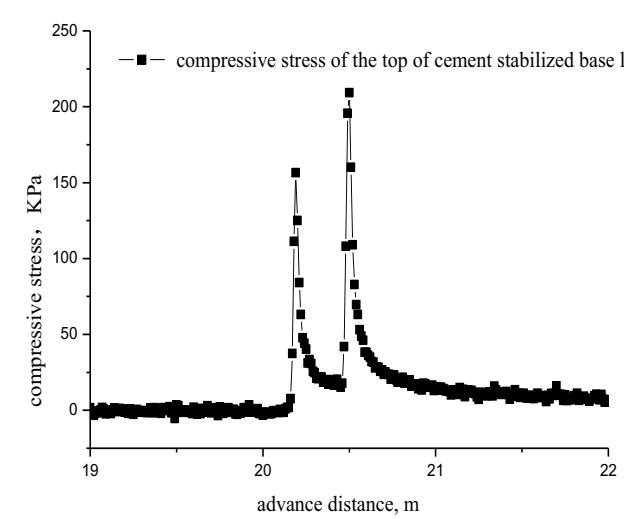

Figure 6. Compressive stress of the top of cement stabilized base.

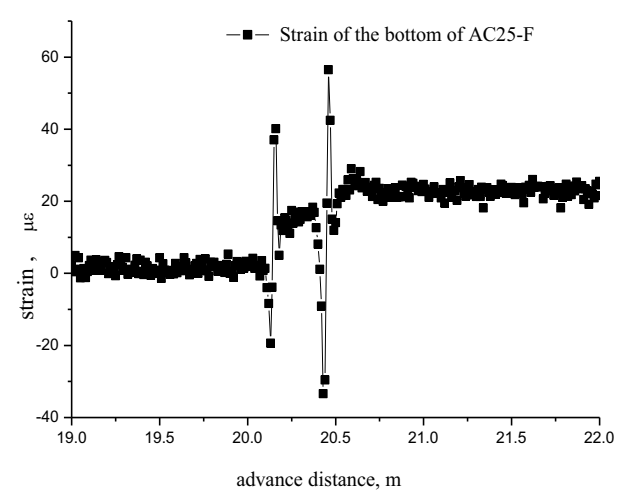

Figure 7. Strain of the bottom of AC25-F.

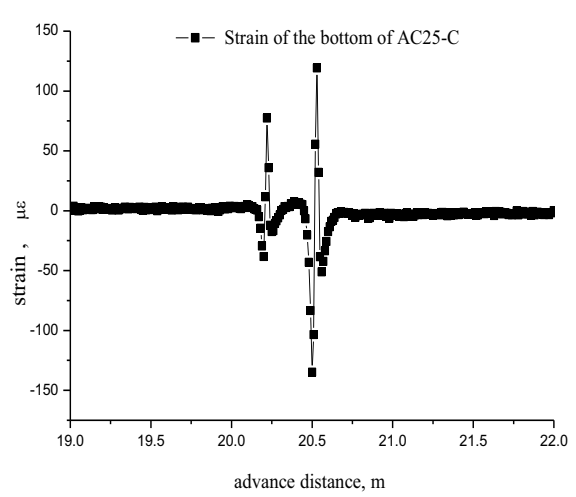

Figure 8. Strain of the bottom of AC25-C.

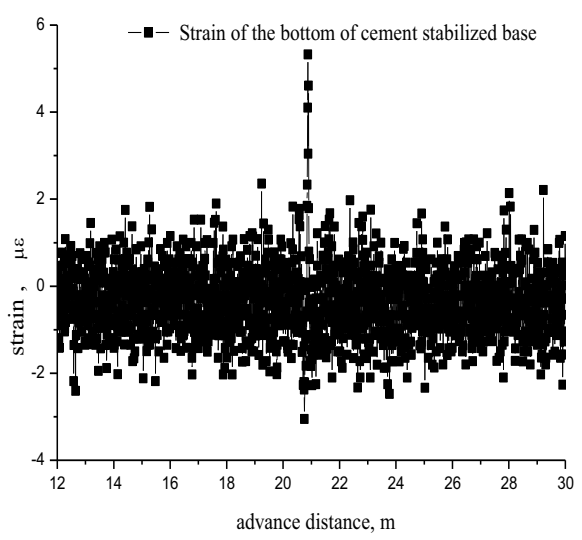

Figure 9. Strain of the bottom of cement stabilized base.

The front and rear wheels of the standard vehicle pass through the instrument embedment position, in the direction of the driving lane, the stress and strain can produce twice wave crest, as the rear wheel is heavier than the front wheel, the second wave significantly higher than the first time. The stress and strain in different structural layers upon the rear are shown as in table 1.

Table 1. Loading response when the rear wheel passed by.

\begin{tabular}{|c|l|}
\hline Type of field data & Test Data \\
\hline Strain in bottom of AC-25F along the lane, $\mu \varepsilon$ & 56.47 \\
\hline $\begin{array}{c}\text { Strain in bottom of AC-25C along the lane, } \\
\text { y }\end{array}$ & 124.22 \\
\hline $\begin{array}{c}\text { Strain in bottom of cement stabilized base } \\
\text { along the Lane, } \mu \varepsilon\end{array}$ & 5.32 \\
\hline vertical stress in bottom of AC25-C & 317.45 \\
\hline vertical stress top of cement stabilized base & 209.30 \\
\hline vertical stress top of graded gravel layer & 23.50 \\
\hline
\end{tabular}

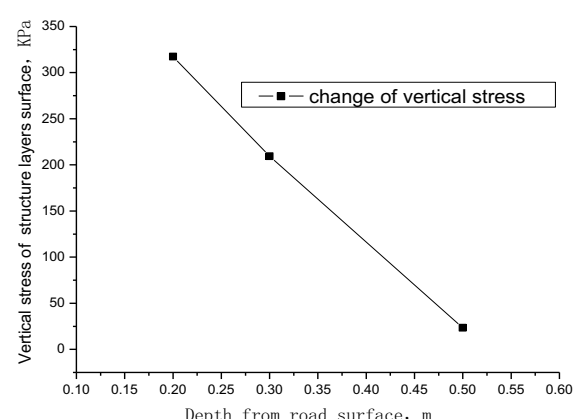

Figure 10. The vertical compressive stress of structural layers surface under loading. 


\section{Test data analysis}

Analyzing the test data, it can be found that relationship between vertical compression and road surface depth is shown as in Fig. 10.

Can be seen from Figure 10, the vertical stress produced by road surface loading is compressive stress, and with depth increasing, stress values gradually decrease, that is stress gradually decreases with loads passing from the top to foundation of the road.

Can be seen from Figure 4 to Figure 9, After the rear wheel of standard truck passed the instruments laying position, strain gradually approach a constant value, Because the viscous and elastic recovery of strain can be completed within a very short period of time, the process of strain reaching a constant value from a maximum value can be considered as a process of standard truck still have an impact on the position of instruments laying. After the standard truck leaving instruments laying position, it can still have an impact on the position of instruments laying within a certain distance. Assuming this distance is "loading effect radius". Loading effect radius of various structural layers is shown in Table 2 .

Table 2. Radius of loading influence of the structural layers under loading.

\begin{tabular}{|l|l|l|}
\hline Layer & Depth, $\mathrm{m}$ & loading effect radius, $\mathrm{m}$ \\
\hline AC25-F & 0.18 & 0.17 \\
\hline AC25-C & 0.26 & 0.12 \\
\hline cement stabilized base & 0.60 & 0.10 \\
\hline
\end{tabular}

Can be seen from Table 2, as the depth increases, the standard truck had a diminishing lading effect radius on different structural layers, This is primarily because vertical loading transmission in the pavement structure is diminishing with depth increases, when the loading passes each layer structure, it will be reduced by dispersing when handed over from upper level, while larger vertical stress in the same structural layers cause wider range of transverse wave.

Instrumental sensor tells strain from extreme gradually returns to a non-zero value before and after loading. Loading makes residual strain happens on structural layers, this fact illustrate that pavement structure as a whole is not a simple linear elastic body, the inherent viscosity and plastic characteristics of structural layer material contribute strain not fully recover after the pavement loading. Specific strain change is shown in Table 3.

Table 3. Strain changes of the structural layers before and after loading.

\begin{tabular}{|l|l|l|l|l|}
\hline & $\checkmark$ & $\begin{array}{l}\text { Extreme strain i } \\
\text { n bottom, } \mu \varepsilon\end{array}$ & $\begin{array}{l}\text { Residual strain in } \\
\text { bottom, } \mu \varepsilon\end{array}$ & $\begin{array}{l}\text { Modulus, } \\
\mathrm{MPa}\end{array}$ \\
\hline AC25-F & 0 & 56.47 & 22.2 & 1335 \\
\hline AC25-C & 0 & -134.78 & -5.0 & 1685 \\
\hline $\begin{array}{l}\text { Cement } \\
\text { stabilized } \\
\text { base }\end{array}$ & 0 & 5.32 & 0.1 & 2850 \\
\hline
\end{tabular}

Can be seen from Table 3, cement stabilized macadam layer is more stable compare with AC25-C layer and AC25-F layer. After the Standard truck leaving the instruments laying position, tension strain can be fully recovered in cement stabilized macadam layer, while AC25-F layer and AC25-C layer has markedly residual tensile strain. This is mainly due to stiffness of cement stabilized macadam is relatively large, and does not have the visco-elastic-plastic properties of asphalt concrete, presents mainly the flexibility before and after the load performance. Visco-plastic property is significant in AC25-F and AC25-C layers, tensile strain at the end layer cannot be fully recovered after the load cancellation. $\mathrm{AC} 25-\mathrm{C}$ is larger in module and higher stiffness than $\mathrm{AC} 25-\mathrm{F}$, resulting in residual strain smaller than AC25-F.

\section{Theoretical analysis}

In China, current pavement design of asphalt concrete pavement for highway taken the pavement as a continuous static layer system, while pavement structure is not a simple elastic layer system, Asphalt concrete is a visco-elastic-plastic material, modulus and load response of grade stone depending on the loading on it, with elastic-plastic characteristics, subgrade is a typical nonlinear materials. All these lead to load response is not a simple elastic response of pavement.

This article takes our country's pavement design specification on the basis, using Abaqus calculation software to analyze the transient load response when the rear wheel reach the instrument laying position, and calculating linear and nonlinear loading response of the road .Model width takes $6 \mathrm{~m}$, depth takes $6.76 \mathrm{~m}$ (assuming the subgrade depth to be $6 \mathrm{~m}$ ), $0.7 \mathrm{MPa}$ surface loads are taken on. Establishing model is shown in Fig. 11 .

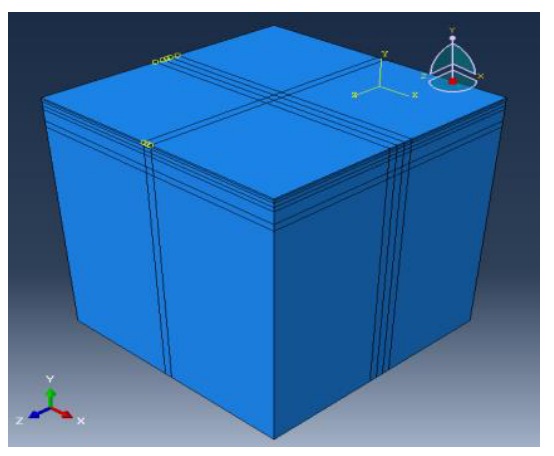

Figure 11. mechanical model.

\subsection{Linear-elastic mechanical models}

Traditional mechanical analysis take the pavement structure as a linear-elastic layer system, various material parameters are shown in Table 4.

Table 4. Material parameters.

\begin{tabular}{|l|l|l|}
\hline & Modulus, MPa & Poisson's ratio \\
\hline SMA-16 & 1644 & 0.3 \\
\hline AC-20 & 1426 & 0.3 \\
\hline AC-25F & 1335 & 0.3 \\
\hline AC-25C & 1685 & 0.3 \\
\hline cement stabilized base & 2850 & 0.25 \\
\hline Graded gravel & 325 & 0.35 \\
\hline Subgrade & 50 & 0.35 \\
\hline
\end{tabular}


Results of Linear elastic analysis are shown in Table 5.

Table 5. Results of Linear elastic analysis.

\begin{tabular}{|l|l|}
\hline Type of field data & Calculating Result \\
\hline $\begin{array}{l}\text { Strain in bottom of AC-25F along the } \\
\text { lane, } \mu \varepsilon\end{array}$ & 23.08 \\
\hline $\begin{array}{l}\text { Strain in bottom of AC-25C along the } \\
\text { Lane, } \mu \varepsilon\end{array}$ & 6.89 \\
\hline $\begin{array}{l}\text { Strain in bottom of cement stabilized } \\
\text { base along the lane, } \mu \varepsilon\end{array}$ & 40.20 \\
\hline vertical stress in bottom of AC25-C & 211.61 \\
\hline $\begin{array}{l}\text { vertical stress top of cement } \\
\text { stabilized base }\end{array}$ & 122.22 \\
\hline $\begin{array}{l}\text { vertical stress top of graded gravel } \\
\text { layer }\end{array}$ & 11.15 \\
\hline
\end{tabular}

\subsection{Non-linear layered system model}

\subsubsection{Mechanical model considering with the material nonlinearity}

Mechanical characteristics for Asphalt concrete, graded gravel and subgrade material do not conform to Hooke law, should not be seen as a simple elastic material. Considering that too much material nonlinearity will lead to model non-convergence, this article only considers subgrade non-linear factor. Mohr Coulomb model, in Abaqus software's materials library, with fewer parameters, can be a good simulation of the soil and mechanical properties of porous materials, So it is taken Mohr Coulomb as subgrade material model, the cohesive forces take 2000Pa, internal friction angle and dilatancy angle respectively taking 20 degrees.

\subsubsection{Considering contacting layers mechanics model}

Assuming that contact surface will never vertically break away while stressing, and pass shear stress through friction in the horizontal direction. In order to guarantee the precision and ease of calculation, this paper processed below treatment to the model in modeling procedure.

(1): consider two surfaces in contact with the same grid, nodes one to one correspondence as far as possible.

(2): when specify mutual contact surfaces, big modulus as the primary surface, small modulus as from surface.

(3): slide mode takes as small slip

Results of nonlinear analysis are shown in Table 6.

Table 6. Calculated values of nonlinear models.

\begin{tabular}{|l|l|l|}
\hline Type of field data & $\begin{array}{l}\text { Subgrade non } \\
\text { linear data }\end{array}$ & $\begin{array}{l}\text { Contacting } \mathrm{n} \\
\text { onlinear Data }\end{array}$ \\
\hline $\begin{array}{l}\text { Strain in bottom of AC-25F along } \\
\text { the lane, } \mu \varepsilon\end{array}$ & 26.02 & 33.22 \\
\hline $\begin{array}{l}\text { Strain in bottom of AC-25C along } \\
\text { the lane, } \mu \varepsilon\end{array}$ & 12.92 & 13.89 \\
\hline $\begin{array}{l}\text { Strain in bottom of cement stabili } \\
\text { zed base along the lane, } \mu \varepsilon\end{array}$ & 35.03 & 37.20 \\
\hline $\begin{array}{l}\text { vertical stress in bottom of AC25 } \\
-\mathrm{C}\end{array}$ & 245.65 & 233.45 \\
\hline $\begin{array}{l}\text { vertical stress top of cement } \\
\text { stabilized base }\end{array}$ & 134.94 & 144.70 \\
\hline $\begin{array}{l}\text { vertical stress top of graded grave } \\
\text { l layer }\end{array}$ & 6.54 & 8.55 \\
\hline
\end{tabular}

\subsection{Results comparison}

Correlation coefficient is a statistical indicator, used to reflect the close relationship between variable variables, can determine the linear dependence of two sets of variables. Results of the analysis model as shown in Table 7.

Table 7. Correlation coefficient between test data and calculated values.

\begin{tabular}{|l|l|l|l|l|}
\hline & $\begin{array}{l}\text { Testing } \\
\text { Data }\end{array}$ & $\begin{array}{l}\text { Linear } \\
\text { elastic } \\
\text { model }\end{array}$ & $\begin{array}{l}\text { Subgrade } \\
\text { nonlinear } \\
\text { model }\end{array}$ & $\begin{array}{l}\text { Contacting } \\
\text { nonlinear } \\
\text { model }\end{array}$ \\
\hline Testing Data & 1 & 0.898677 & 0.920612 & 0.919697 \\
\hline
\end{tabular}

Can be seen from Table 7, three models are able to react loading response of pavement very good, Calculation results of subgrade non-linear model \& nonlinear contacting model is more similar to test result compare with linear elastic models, which simulate better actual loading response of pavement conditions, which is also consistent with actual working condition of the road.

\section{Conclusions}

(1) When the standard truck pass through instruments laying position, vertical stress produced by loads within the pavement structure is declining from top layer to bottom layer.

(2) Due to the decline characteristics when loads passed from top to bottom layer in pavement structure, as the depth increases, the standard truck "load effect radius" in different structural layers is diminishing

(3) Before and after loading, tensile strain at the end of the cement stabilized macadam layer can be fully recorded, AC25-C and AC25-F layers with greater residual tensile strain; Due to the low modulus and more significant visco-plastic than AC25-C, AC25-F gains more residual strain.

(4) Both linear elastic model and nonlinear model can well simulate the load response of road structure; Calculation results of subgrade non-linear model \& nonlinear contacting model is more similar to test result compare with linear elastic models, which is also consistent with actual working condition of road.

\section{References}

1. D. Zhang, Asphalt and Asphalt Mixture, Beijing: People's Communications Publishing House,:42-54, (1993)

2. X. Zhang, Experimental Viscoelastic Theory (Heilongjiang: Harbin Shipbuilding Engineering Institute Press, 1990: 20-60)

3. J. Yuan, X. Huang, Journal of Chang'an University (Natural Science Edition ) 6, (2007)

4. J. Mallela, K. P. George, Transportation Research Record 1448, 92-99, (1995)

5. H. Luo, H. Zhu, X. Hao, Journal of China University of Geosciences 17, 4, 349-354, (2006)

6. X. Deng, C. Li, Chinese Journal Of Geotechnical Engineering 4, (2002) 